Check for updates

Cite this: RSC Adv., 2017, 7, 44908

Received 1st August 2017

Accepted 7th September 2017

DOI: $10.1039 / \mathrm{c} 7 \mathrm{ra0} 8490 \mathrm{k}$

rsc.li/rsc-advances

\section{Tailoring light emission properties and optoelectronic and optothermal responses from rare earth-doped bismuth oxide for multifunctional light shielding, temperature sensing, and photodetection $\dagger$}

\author{
Liumin Fan, ${ }^{a}$ Yang Li, ${ }^{\text {ab }}$ Xiaohui Lin, ${ }^{a}$ Junhao Peng, ${ }^{a}$ Guifang Ju, (D) ${ }^{a}$ Shaoan Zhang, ${ }^{\text {ad }}$ \\ $\mathrm{Li}$ Chen, ${ }^{a}$ Fupo $\mathrm{He}^{c}$ and Yihua $\mathrm{Hu}$ (D)*a
}

\begin{abstract}
Multifunction and high integration has always been a goal worth pursuing when important breakthroughs of multidisciplinary researches in the fields of thermo-luminescent, opto-electronic, photo-magnetic interaction, etc., are emerged. Other significant considerations for a multifunctional strategy proposed in a single-material system are low-cost components and processing, universal applicability, and widespread popularity. Herein, we developed an all-purpose material with a tunable light emission property and controllable optoelectronic and optothermal response process. We showed a disappearance of emission behavior under the excitation of UV light by building a mid-gap host $\left(\mathrm{Bi}_{2} \mathrm{O}_{3}\right)$ along with a rare earth $\left(\mathrm{Sm}^{3+}\right)$ ion, with multiple energy level configurations, as an emission center. We also demonstrated that this scheme realized the successful imbedding of higher energy level $\mathrm{Sm}^{3+}$ into the conduction band and led to increased current under the excitation of visible light and the depopulated redistribution of the excited state level near the conduction band at higher temperatures. Thus, this phosphor is expected to open up the possibility of potentially free choice of light shielding, temperature sensing, and photodetection in a single-material system.
\end{abstract}

\section{Introduction}

The famous energy band gap (EBG) engineering has often been utilized to design inorganically functional materials. From the plausible crystallographic model, it is possible to customize the spectroscopic feature for a given fluorescent material by employing the EBG theory and engineering route. Typically, the electron migration process of activators along with the related photoluminescence (PL) and photoluminescence excitation (PLE) bands can be tailored via tuning the energy band gap as some transition levels of activators between forbidden bands are invalid when they are deeply embedded into the conduction band (CB) (Fig. 1). ${ }^{1-5}$ It is noteworthy that the PLE bands of rareearth or transition metal ions, which are employed in

${ }^{a}$ School of Physics and Optoelectronic Engineering, Guangdong University of Technology, Guangzhou 510006, China.E-mail: huyh@gdut.edu.cn; lychris@sina.com ${ }^{b}$ State Key Laboratory of Luminescent Materials and Devices, South China University of Technology, Guangzhou 510640, China

${ }^{c}$ School of Electromechanical Engineering, Guangdong University of Technology, Guangzhou 510006, China

${ }^{d}$ Guangzhou Maritime University, Guangzhou 510006, China

$\dagger$ Electronic supplementary information (ESI) available. See DOI: 10.1039/c7ra08490k a phosphor as luminescent centers, vary greatly with the forbidden bandwidth of the crystals used as a parent. The controlled use of middle band gap phosphors in combination with a careful choice of suitable activators finds important and widespread applications in the fields of optical shielding and sensing. Moreover, the precisely controlled forbidden bandwidth is also a pivotal determinant of migration performance of activated carriers in the conduction band. A suitable band gap can increase the number of hot and light-activated carriers at room temperature, enhance the migration rate of these carriers in the conduction band (Fig. 1), thus greatly optimize the optoelectronic response process, and open the possibility of designing new multifunctional optoelectronic devices with the integrated characteristics of light shielding, sensing, and detection in a single-material system.

In the past few years, numerous materials only featuring single optical or optoelectronic properties have been reported and widely used as a nanothermometer or nanogenerator. ${ }^{6-9}$ Currently, ZnO has a middle, direct band gap of $3.3 \mathrm{eV}$, and it has been considered as the superior candidate of a UV sensor and energy harvester; this shows its potential application in a wide range of fields such as in biological and chemical analysis, astronomical studies, flame sensing, and early missile plume detection. ${ }^{\mathbf{1 0 , 1 1}}$ Besides, the optical properties of a $\mathrm{Ag}_{2} \mathrm{~S}$ 


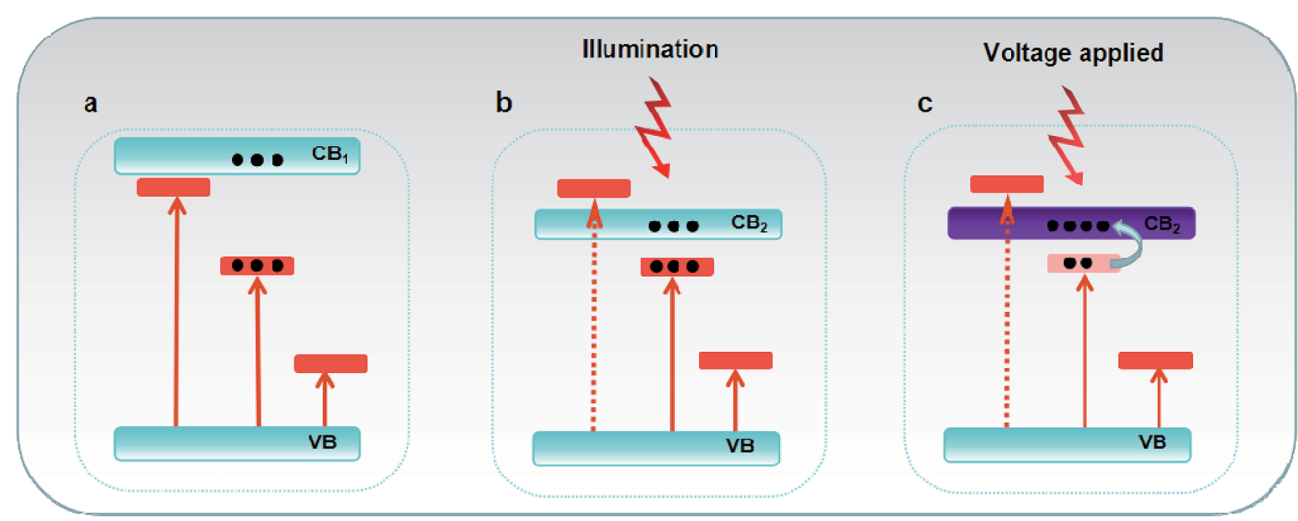

Fig. 1 Energy band model depicting the possible variation in electron transition and migration in a narrower band gap material. (a) Energy band model of broad band gap material. Energy band model of the narrow band gap material depicting (b) the disappearance of short-wave excitation band, and (c) the enhancement of photocurrent under the excitation of visible light.

nanoparticle, carbon dot or rare-doped fluoroscope show relevant temperature dependence in the physiological temperature range; this triggers the application of these materials as nanothermometers for in vivo imaging and hyperthermia treatments. ${ }^{11-19,40}$

Moreover, short wavelength and high energy can destroy the covalent bonds (e.g., C-H, C-C, and $\mathrm{C}-\mathrm{Cl}$ ) of organic substances and cause incurable damages to cells in the retina of the human eye, which result in serious damages to commonly used organic materials, as well as human health. Therefore, the development of light-shielding materials has attracted significant attention in the field of coatings and sunscreen to reduce the destruction by short-wavelength irradiation. Generally, inorganic lightshielding materials (e.g., $\mathrm{TiO}_{2}, \mathrm{ZnO}, \mathrm{SiO}_{2}$, and $\mathrm{Al}_{2} \mathrm{O}_{3}$ ) have been widely used owing to their optical and thermal stability as well as nontoxicity. However, their photocatalytic activity as a side effect would simultaneously induce photo-degradation of organic substances. In addition, the application areas of these materials are limited. Therefore, it is necessary to search for novel lightshielding materials with high stability, excellent light-shielding behavior, and multifunction..$^{19,20}$ It is clear that these kinds of function materials, photon, photo-thermal, and photoelectric interactions are essential. Multifunction and integration are always fascinating; if these characters can be integrated into a single-material system, it will result in a new type of low-cost, multipurpose, and more popular functional materials.

Herein, we developed an integratedly functional material with tunable light emission property and controllable optoelectronic and optothermal response processes by building a mid-gap host along with a $\mathrm{Sm}^{3+}$ ion with multiple energy level configuration as an emission center and realized the potentially free choice of multifunctional light shielding, temperature sensing, and photodetection in a single-material system. The main purpose of this study was to demonstrate the fundamental physical phenomenon in interdisciplinary research, such as in optical, opto-thermal, and opto-electronic multidisciplinary projects.

As a proof-of-concept experiment, top-priority spectroscopic investigation starts from the choice of the host material.
Compared with sulfide and selenide, oxide usually has a larger forbidden bandwidth due to its relatively smaller atomic radius although heavy element oxides have enough ability to cover this shortage due to their larger cation radius along with short band gap. ${ }^{21,39}$ In recent years, significant interest has been generated in research on bismuth trioxide $\left(\mathrm{Bi}_{2} \mathrm{O}_{3}\right)$ due to its unique properties such as middle band gap, high electrical conductivity, and remarkable electron mobility. These properties enable the multifarious applications of $\mathrm{Bi}_{2} \mathrm{O}_{3}$ in gas sensor technology and microelectronics and as a photocatalyst and photoanode for dye-sensitized solar cells. Owing to the abundant transition energy level, trivalent lanthanide ions are of great interest for a wide range of applications. The excitation and emission of lanthanides span over the entire spectrum ranging from ultraviolet (UV) to near-infrared (NIR) regions, as determined by the chemical nature of lanthanide ions, except that $\mathrm{La}^{3+}$ and $\mathrm{Lu}^{3+}$ have no luminescence. Herein, $\mathrm{Sm}^{3+}$ ions were employed as representatives of emission center in this material system.

Fig. 1 shows the possible variation in electron transition and migration in a narrower band gap material. The successful imbedding of higher energy-level of activators into the conduction band dominates the overall dynamic behavior of high-energy photon in the Sm-doping $\mathrm{Bi}_{2} \mathrm{O}_{3}$ phosphor, including the disappearance of short-wave excitation band, the enhancement of photocurrent under the excitation of visible light, and depopulated redistribution of the excited state near the conduction band at higher temperatures, of the high-energy photon in the $\mathrm{Sm}$-doped $\mathrm{Bi}_{2} \mathrm{O}_{3}$ phosphor.

\section{Experimental}

\section{Materials}

A series of samples $\mathrm{Bi}_{2} \mathrm{O}_{3}: x \mathrm{Re}^{3+}\left(x \mathrm{Re}^{3+}=0.3 \% \mathrm{Sm}^{3+}, 1 \% \mathrm{Nd}^{3+}\right.$, and $2 \% \mathrm{Eu}^{3+}$ ) was prepared by a conventional solid-state reaction process. The starting materials were $\mathrm{Bi}_{2} \mathrm{O}_{3}(99.99 \%), \mathrm{Sm}_{2} \mathrm{O}_{3}$ (99.99\%), $\mathrm{Nd}_{2} \mathrm{O}_{3}(99.99 \%)$, and $\mathrm{Eu}_{2} \mathrm{O}_{3}(99.99 \%)$. All chemicals were used directly in an agate mortar and mixed, and then, the mixtures were sintered at $800{ }^{\circ} \mathrm{C}$ for $6 \mathrm{~h}$. 


\section{Characterization}

Crystal morphologies of the resulting materials were determined using an X-ray diffractometer equipped with a $\mathrm{Cu} \mathrm{K} \alpha$ radiation source $(\lambda=1.5405 \AA)$ at $36 \mathrm{kV}$ tube voltage and $20 \mathrm{~mA}$ tube current. Ultraviolet-visible absorption measurements were conducted via a UV-2450 spectrophotometer (Shimadzu UV2450, Japan) using $\mathrm{BaSO}_{4}$ as a reference. PL, PLE, and temperature-induced PL spectra were obtained by a highresolution spectrofluorometer (UK, Edinburgh Instruments, FLS980) equipped with a $500 \mathrm{~W}$ xenon lamp as an excitation source. The current-voltage $(I-V)$ curves of the samples under different wavelengths were obtained using a Radiant Technologies Precision premier II Ferroelectric Tester (Albuquerque, NM, USA). To prepare the sample for $I-V$ curve measurements, $\mathrm{Bi}_{2} \mathrm{O}_{3}: x \mathrm{Re}^{3+}\left(x \mathrm{Re}^{3+}=0.3 \% \mathrm{Sm}^{3+}, 1 \% \mathrm{Nd}^{3+}\right.$, and $\left.2 \% \mathrm{Eu}^{3+}\right)$ were pressed into discs with a diameter of $80 \mathrm{~mm}$ using a $50 \mathrm{~kg}$ press and electroded with silver. To explore the effect of $\mathrm{pH}$ on the emission intensity, $0.5 \mathrm{~mL}$ of hydrochloric acid (the $\mathrm{pH}$ value ranging from 2 to 6 ), $0.5 \mathrm{~mL}$ of sodium hydroxide solution (the $\mathrm{pH}$ value ranging from 8 to 12 ), and $0.5 \mathrm{~mL}$ of deionized water were added dropwise to $0.2 \mathrm{~g}$ of the $\mathrm{Bi}_{2} \mathrm{O}_{3}: 0.3 \% \mathrm{Sm}^{3+}$ sample. The mixtures were centrifuged for $10 \mathrm{~min}$ in deionized water. In addition, the $\mathrm{pH}$-inducing spectra were obtained using a highresolution spectrofluorometer (UK, Edinburgh Instruments, FLS980).

\section{Results and discussion}

\section{Structural analysis}

Herein, we have discussed the band gap of the $\mathrm{Bi}_{2} \mathrm{O}_{3}$ sample via the theoretical calculation (Fig. 2a). The results show that $\mathrm{Bi}_{2} \mathrm{O}_{3}$ semiconductor has a middle, direct band gap of $2.13 \mathrm{eV}$ (more details with respect to the calculation process for theoretical band gap of bismuth oxide are provided in the ESI $\dagger$ ). Fig. $2 b$ presents the three-dimensional structure of $\alpha-\mathrm{Bi}_{2} \mathrm{O}_{3}$. It crystallizes in the $P 2_{1} / c$ space group of a known monoclinic phase with the lattice parameters of $a=0.58496(3) \mathrm{nm}, b=0.81648(4) \mathrm{nm}$, and $c=0.75101(4) \mathrm{nm}^{21-24}$ There are two $\mathrm{Bi}^{3+}$ sites (Bi-I and Bi-
II) and three $\mathrm{O}^{2-}$ sites. The $\mathrm{Bi}-\mathrm{I}$ atoms and $\mathrm{Bi}-\mathrm{II}$ atoms consist of six-fold coordination by six $\mathrm{O}$ and five-fold coordination by five $\mathrm{O}$, respectively. A six-coordinated $\mathrm{Bi}^{3+}$ and six $\mathrm{O}^{2-}$ form a distorted octahedron, which can provide possible non-center symmetrical sites for possible $\mathrm{Sm}^{3+}$ ions. Additionally, the ionic radius of Bi-I ions (1.03 $\AA$ ) is similar to that of $\mathrm{Sm}^{3+}$ ions $(0.958 \AA) .{ }^{21,23}$ Due to the suitable ionic radii, valence state, and crystal structure, $\mathrm{Sm}^{3+}$ can preferentially occupy the sites of Bi-I ions to realize the potential of the $\mathrm{Sm}^{3+}$-doped mid-gap material in the field of multifunctional light shielding, sensing, and detection. XRD data further confirmed the abovementioned structural analysis (Fig. 3). The acquired XRD pattern of $\mathrm{Bi}_{2} \mathrm{O}_{3}: \mathrm{Sm}^{3+}$ is similar to that of $\mathrm{Bi}_{2} \mathrm{O}_{3}$, and all the diffraction peaks of these samples are well indexed to the JCPDS no. 652366. The similar crystal structure can also be observed in the XRD data of $\mathrm{Bi}_{2} \mathrm{O}_{3}: \mathrm{Nd}^{3+}$ and $\mathrm{Bi}_{2} \mathrm{O}_{3}: \mathrm{Eu}^{3+}$ phosphors (Fig. $\mathrm{S} 1 \dagger$ ).

To better evaluate the band gap, the experimental diffuse reflectance measurements of $\mathrm{Bi}_{2} \mathrm{O}_{3}$ and $\mathrm{Bi}_{2} \mathrm{O}_{3}: \mathrm{Sm}^{3+}$ phosphor were carried out, and the results converted via the KubelkaMunk function $F(R)$ (Fig. 2c and S3†). As is known, the correlation between the optical band gap $E_{1}$ and the absorption

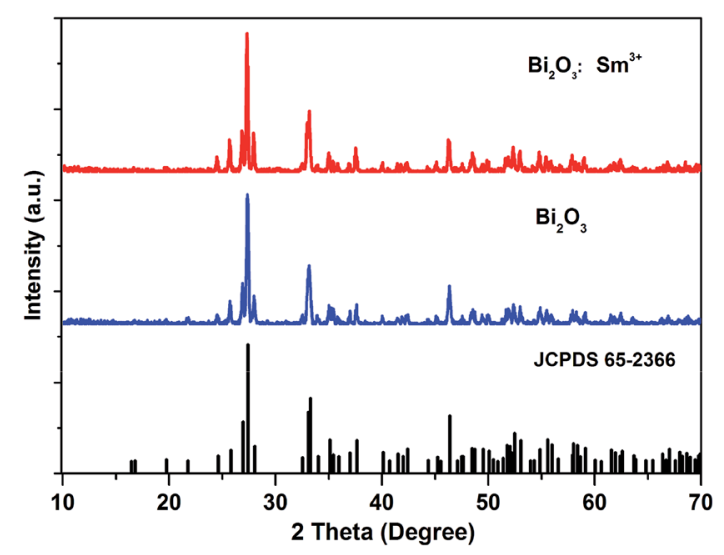

Fig. 3 The XRD patterns of $\mathrm{Bi}_{2} \mathrm{O}_{3}$ and $\mathrm{Bi}_{2} \mathrm{O}_{3}: \mathrm{Sm}^{3+}$ with the PDF card of $\mathrm{Bi}_{2} \mathrm{O}_{3}$.
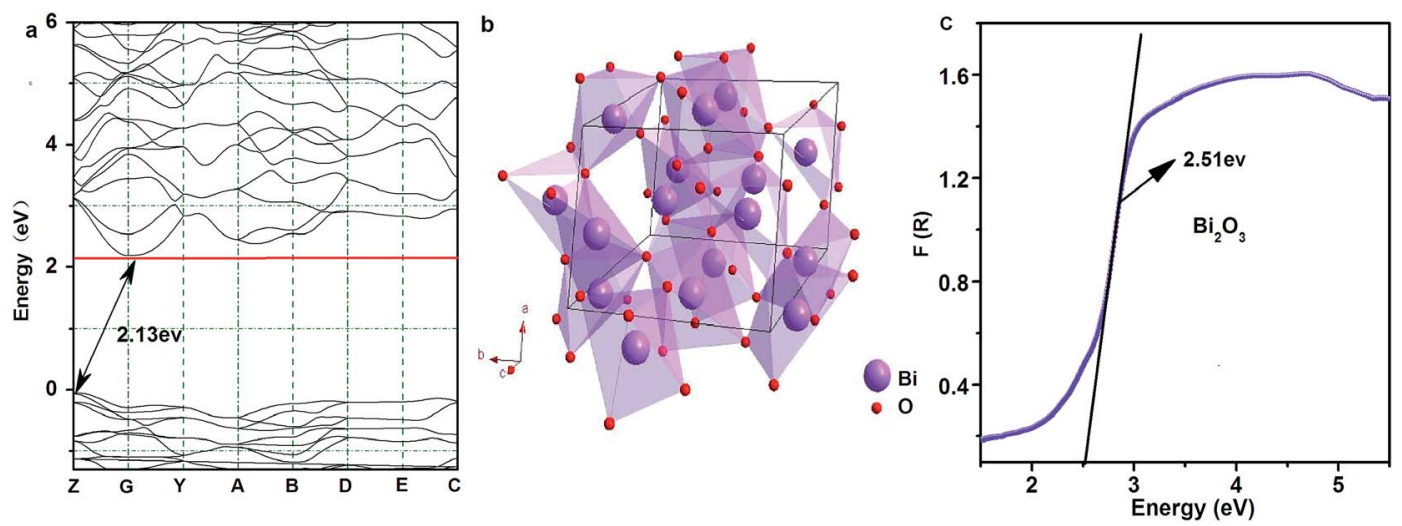

Fig. 2 The Structural analysis of the $\mathrm{Bi}_{2} \mathrm{O}_{3}$ phosphor. (a) Calculated band structure of $\mathrm{Bi}_{2} \mathrm{O}_{3}$. (b) Crystal structure of $\mathrm{Bi}_{2} \mathrm{O}_{3}$. (c) Converted diffuse reflectance spectrum of $\mathrm{Bi}_{2} \mathrm{O}_{3}$ host via the Kubelka-Munk function $F(R)$. The band gap energy for the sample was estimated from the intercept of a fitted straight line (black). 
coefficient of semiconductor oxides can be described through the following well-known equation: ${ }^{25}$

$$
\alpha E \approx A_{1}\left(E-E_{1}\right)^{m}
$$

where $A_{1}$ is a constant, $E=h \nu$ is the photon energy, and $m=1 / 2$ (for allowed direct electronic transition), 2 (for allowed indirect electronic transition), 3/2 (for forbidden direct electronic transition), or 3 (for forbidden indirect electronic transition). In our study, $\mathrm{Bi}_{2} \mathrm{O}_{3}$ is a direct band gap material. Therefore, the Kubelka-Munk function is related as follows: ${ }^{26}$

$$
\begin{gathered}
F(R)=(1-R)^{1 / 2} / 2 R=k / s \\
{[h v F(R)]^{2}=A_{2}\left(h v-E_{1}\right)}
\end{gathered}
$$

where $R$ is the reflectivity of the sample, $k$ is the molar absorption coefficient of the sample, and $s$ is the scattering coefficient. Therefore, we can obtain $F(R)$ from eqn (2) and (3) (the eqn (3) can be obtain by using eqn (1) and (2)). In the plot of $[h v F(R)]^{2}$ versus $h v$, the values of the optical band gap $E_{1}$ of samples are obtained by extrapolating the linear fitted regions to $[h v F(R)]^{2}=0$. Therefore, the experimental values of the band gap $E_{1}(2.51 \mathrm{eV})$ are in agreement with our theoretical calculation (Fig. 2a). The experimental value and the theoretical calculation of band gap are shown in Fig. S2 and S3, $\uparrow$ respectively. As expected, $\mathrm{Sm}^{3+}$ ion is easily precipitated into the targeted lattice site according to the abovementioned theoretical assumption. Therefore, the optical characteristics of $\mathrm{Sm}^{3+}$ ions in the $\mathrm{Bi}_{2} \mathrm{O}_{3}$ host have been discussed hereinafter.

\section{No emission behavior under the excitation of UV light}

It has been demonstrated that UV light can be successfully absorbed by the $\mathrm{Bi}_{2} \mathrm{O}_{3}: \mathrm{Sm}^{3+}$ phosphor (Fig. 4); however, $\mathrm{Bi}_{2} \mathrm{O}_{3}: \mathrm{Sm}^{3+}$ does not exhibit the conventional emission behavior under the excitation of UV light. PL and PLE spectra of the $\mathrm{Bi}_{2} \mathrm{O}_{3}: \mathrm{Sm}^{3+}$ sample are shown in Fig. $4 \mathrm{a}$ and $\mathrm{b}$, respectively. The emission spectra constitute many typical transition bands centered at $560 \mathrm{~nm}, 609 \mathrm{~nm}$, and $653 \mathrm{~nm}$ under $490 \mathrm{~nm}$ excitation, which can be ascribed to the electronic transitions of $\mathrm{Sm}^{3+}$ from ${ }^{4} \mathrm{G}_{5 / 2}$ to ${ }^{6} \mathrm{H}_{5 / 2},{ }^{6} \mathrm{H}_{7 / 2}$, and ${ }^{6} \mathrm{H}_{9 / 2}$, respectively. ${ }^{27,28}$ The splitting of typical emission bands is known to be dependent on the crystal field effect, which is caused by the static electric charges in the bismuth-oxide host. ${ }^{29}$ PLE spectra exhibit the obvious excitation bands peaking at 470 and $490 \mathrm{~nm}$ in the visible region of 450-500 nm when monitored under $653 \mathrm{~nm}$ emission. They are due to the ${ }^{6} \mathrm{H}_{5 / 2} \rightarrow{ }^{4} \mathrm{I}_{13 / 2}$ and ${ }^{6} \mathrm{H}_{5 / 2} \rightarrow{ }^{4} \mathrm{I}_{11 / 2}$ transitions of $\mathrm{Sm}^{3+}$. It should be noted that the characteristic excitation band of $\mathrm{Sm}^{3+}$ in $\mathrm{Bi}_{2} \mathrm{O}_{3}: \mathrm{Sm}^{3+}$ is completely different from that of the material system reported to date. Usually, the excitation bands at $346,362,377,404$, and $417 \mathrm{~nm}$ can be traced in the PLE spectra of $\mathrm{Sm}^{3+}$-doped $\mathrm{NaSrBO}_{3}, \mathrm{NaGdF}_{4}$, and $\mathrm{GdVO}_{4} \cdot{ }^{29-31}$ However, there is no PLE band in the UV regions between $250 \mathrm{~nm}$ and $450 \mathrm{~nm}$, as shown in Fig. 4a. The fluorescent decay curves provide the validity of visible excitation as well (Fig. S4 $\dagger$ ). Therefore, $\mathrm{Sm}^{3+}$ ions can be excited to the ${ }^{4} \mathrm{I}_{13 / 2}$ level by $470 \mathrm{~nm}$ light, and then, the excited energy relaxes to the ${ }^{4} \mathrm{G}_{5 / 2}$ level by non-radiative relaxation. Emission takes place in the transition process between ${ }^{4} \mathrm{G}_{5 / 2}$ level and ${ }^{6} \mathrm{H}_{9 / 2},{ }^{6} \mathrm{H}_{7 / 2}$, and ${ }^{6} \mathrm{H}_{5 / 2}$ levels. The higher excitation energy may lead to the delocalization of the excited electron across the conduction band into the vacuum level, and then, this electron finally becomes a free electron (Fig. 4c). A similar optical phenomenon can also be observed in PL and PLE spectra of the $\mathrm{Bi}_{2} \mathrm{O}_{3}: \mathrm{Nd}^{3+}$ and $\mathrm{Bi}_{2} \mathrm{O}_{3}: \mathrm{Eu}^{3+}$ phosphors (Fig. S5 and $\mathrm{S} 6 \dagger$ ).

\section{Optoelectronic detection}

This scheme containing mid-gap host and $\mathrm{Sm}^{3+}$ ions has already proved their potential as a new light-shielding material. The light-controlling current response is another important characteristic. Fig. 5 presents the optoelectronic performance of the $\mathrm{Bi}_{2} \mathrm{O}_{3}: \mathrm{Sm}^{3+}$ phosphor. The stable $I-V$ curve of $\mathrm{Bi}_{2} \mathrm{O}_{3}: \mathrm{Sm}^{3+}$ as a function of the bias voltage of $30 \mathrm{~V}$ is first shown in Fig. 5a, which is obtained under the excitation of monochromatic light with different wavelengths $(254,460$, and $590 \mathrm{~nm})$. The corresponding peak current at a bias of $30 \mathrm{~V}$ is plotted as a function of wavelength, as shown in Fig. 5b. The dark current $(\sim 0.70 \mu \mathrm{A})$ is found to be lowest, whereas the current under the excitation of 254,460 , and $590 \mathrm{~nm}$ light reaches $\sim 0.81, \sim 1.15$, and $\sim 0.99$ $\mu \mathrm{A}$, respectively; this is in accordance with an increase of $15.71 \%, 64.29 \%$, and $41.43 \%$ for the current under the excitation as compared to that of the dark current. The timedependent optoelectronic response of $\mathrm{Bi}_{2} \mathrm{O}_{3}: \mathrm{Sm}^{3+}$ exposed to
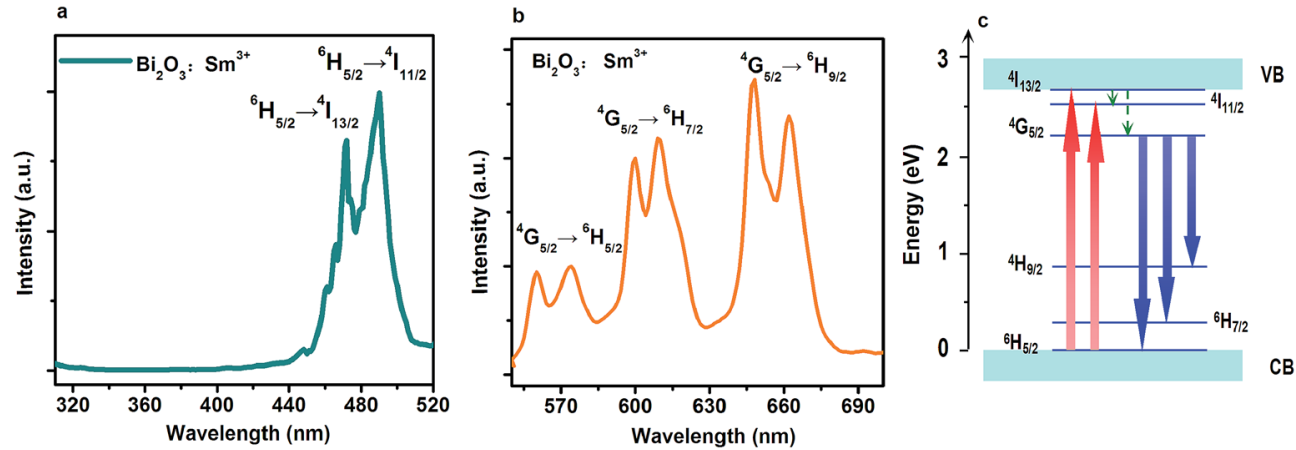

Fig. 4 The optical characteristics of the $\mathrm{Bi}_{2} \mathrm{O}_{3}: \mathrm{Sm}^{3+}$ phosphor: (a) PLE $\left(\lambda_{\mathrm{em}}=653 \mathrm{~nm}\right)$ and (b) PL spectra $\left(\lambda_{\mathrm{ex}}=490 \mathrm{~nm}\right)$ of $\mathrm{Bi}_{2} \mathrm{O}_{3}: \mathrm{Sm}^{3+}$ phosphor. (c) Schematic of the energy levels of $\mathrm{Sm}^{3+}$ ions in the $\mathrm{Bi}_{2} \mathrm{O}_{3}: \mathrm{Sm}^{3+}$ phosphor. 

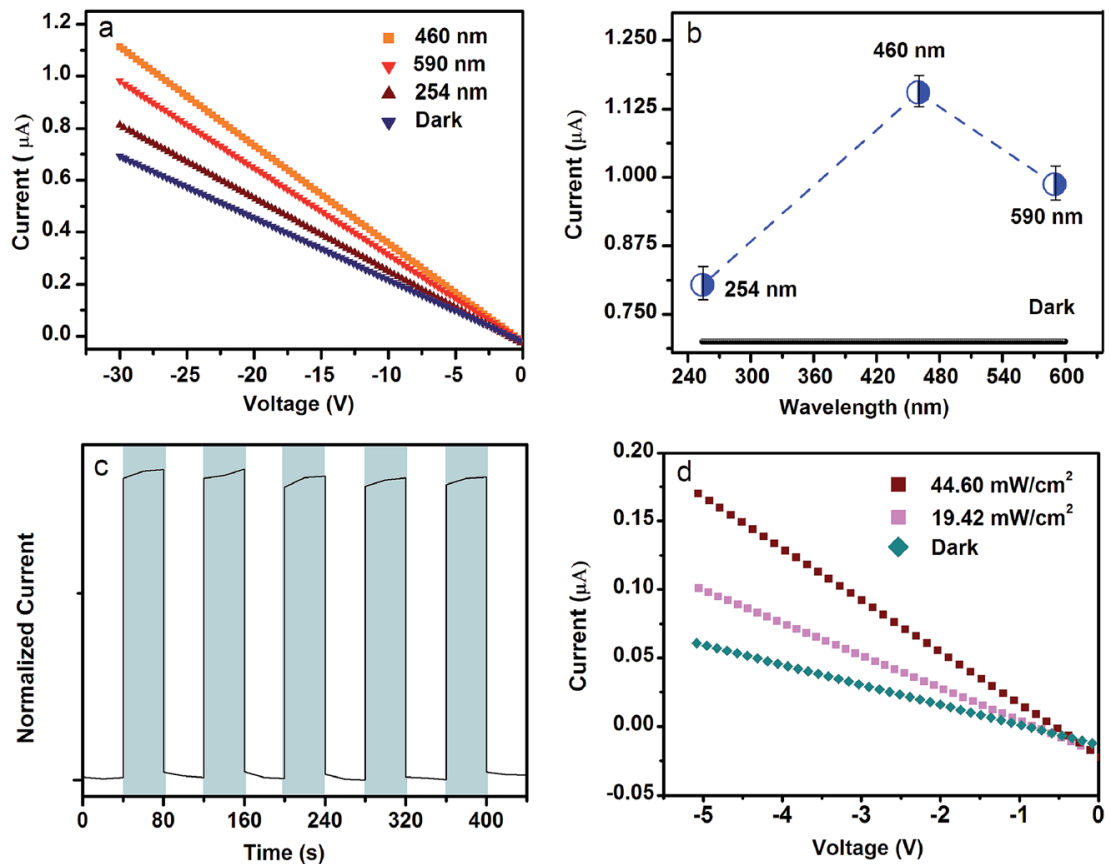

Fig. 5 The optoelectronic performance of the $\mathrm{Bi}_{2} \mathrm{O}_{3}: \mathrm{Sm}^{3+}$ phosphor. (a) The current response without and with the irradiation of 254,460 , and $590 \mathrm{~nm}$ light as a function of bias voltage. (b) The current without and with the irradiation of 254, 460, and $590 \mathrm{~nm}$ light at a bias voltage of $30 \mathrm{~V}$. (c) Time-resolved current response of $\mathrm{Bi}_{2} \mathrm{O}_{3}: \mathrm{Sm}^{3+}$ under visible light irradiation $(460 \mathrm{~nm})$. (d) $I-V$ measurements conducted at different illumination intensities.

a $460 \mathrm{~nm}$ excitation source is depicted in Fig. 5c. The current sharply increases during periodical excitation of light illumination. Furthermore, there are no obvious increases/decreases for the current under illumination in each cycle. The response process is fast, and the corresponding current is stable; this indicates that this material is reliable and repeatable. Fig. $5 \mathrm{~d}$ presents the result of the $I-V$ measurements with blue illumination. It can be seen that an increase in peak current is achieved by increasing the illumination intensity at a bias of $5 \mathrm{~V}$. Obviously, the current $(\sim 0.10$ and $\sim 0.17 \mu \mathrm{A})$ at a fixed illumination intensity of 19.42 and $44.60 \mathrm{~mW} \mathrm{~cm}^{-2}$ is an order of magnitude ( $\sim 66.67 \%$ and $\sim 183.33 \%$ times) higher than the dark current $(\sim 0.06 \mu \mathrm{A})$. All the investigation about current can be applied to detect the subtle variation in the intensity of the observed light. The similar optoelectronic performance of $\mathrm{Bi}_{2} \mathrm{O}_{3}: \mathrm{Nd}^{3+}$ phosphors can also be observed in Fig. S8. $\uparrow$ Therefore, the material can be used as a calibrated optoelectronic detection material in the required spectral range.

\section{Temperature sensing and chemical stability}

A multifunctional photosensor can extract the information by detecting the variation in emission spectra in an unstable environment. Temperature is a fundamental physical parameter in chemical and biological systems. Therefore, the temperature sensor aims to deliver the knowledge of the local temperature in a given system, which is required for submicrometric spatial resolution. ${ }^{6,27,32-35}$ Fig. 6a shows the PL spectra of the $\mathrm{Bi}_{2} \mathrm{O}_{3}: \mathrm{Sm}^{3+}$ phosphor excited at $490 \mathrm{~nm}$ at different temperatures $\left(50,80\right.$, and $\left.100{ }^{\circ} \mathrm{C}\right)$. The peak intensity monitored at different temperatures ranging from 50 to $100{ }^{\circ} \mathrm{C}$ shows a distinct decline. $\mathrm{Sm}^{3+}$ ion presents electronic states very close in energy such that they are thermally coupled. The population distribution in thermally coupled states is strongly temperature dependent as it is governed by Boltzmann statistics. Therefore, any slight modification in the temperature causes relevant modifications in the population of the thermally coupled states. $^{36-38}$

Apart from the temperature-induced population redistribution, temperature-induced spectral shift is also observed in the PL spectra at different treatment temperatures. ${ }^{33,37}$ Temperature variation leads to modifications in the arrangement of lattice ions surrounding $\mathrm{Sm}^{3+}$ ions. Therefore, crystal field is modificated, which results in a red-shift in the $\mathrm{Sm}^{3+}$ emission lines. The temperature dependency of the intensity ratio at $653 \mathrm{~nm}$ emission band and spectra shift between 559 and $562 \mathrm{~nm}$ are shown in Fig. $6 a$ and b. The thermal sensitivity is calculated from the experimental data included in Fig. $6 \mathrm{c}$. The value of the error bar is very small, which proves that the results are reliable and the properties of the prepared material are stable. The calculation process is presented in the ESI. $\dagger$ Maximum thermal sensitivity is obtained, and it results from temperature dependence of the intensity and spectral shift being close to $0.98 \%{ }^{\circ} \mathrm{C}^{-1}$ and $1.13 \%{ }^{\circ} \mathrm{C}^{-1}$, respectively, which is larger than the value of thermal sensitivity of green fluorescent protein $\left(0.4 \%{ }^{\circ} \mathrm{C}^{-1}\right) \cdot{ }^{36}$ The similar optothermal performance of the $\mathrm{Bi}_{2} \mathrm{O}_{3}: \mathrm{Eu}^{3+}$ phosphors can also be observed in Fig. S7. $\dagger$

In this study, to identify the chemical stability of the asprepared sample, the intensity variation of emission peak induced by the $\mathrm{pH}$ value is investigated in an aqueous 

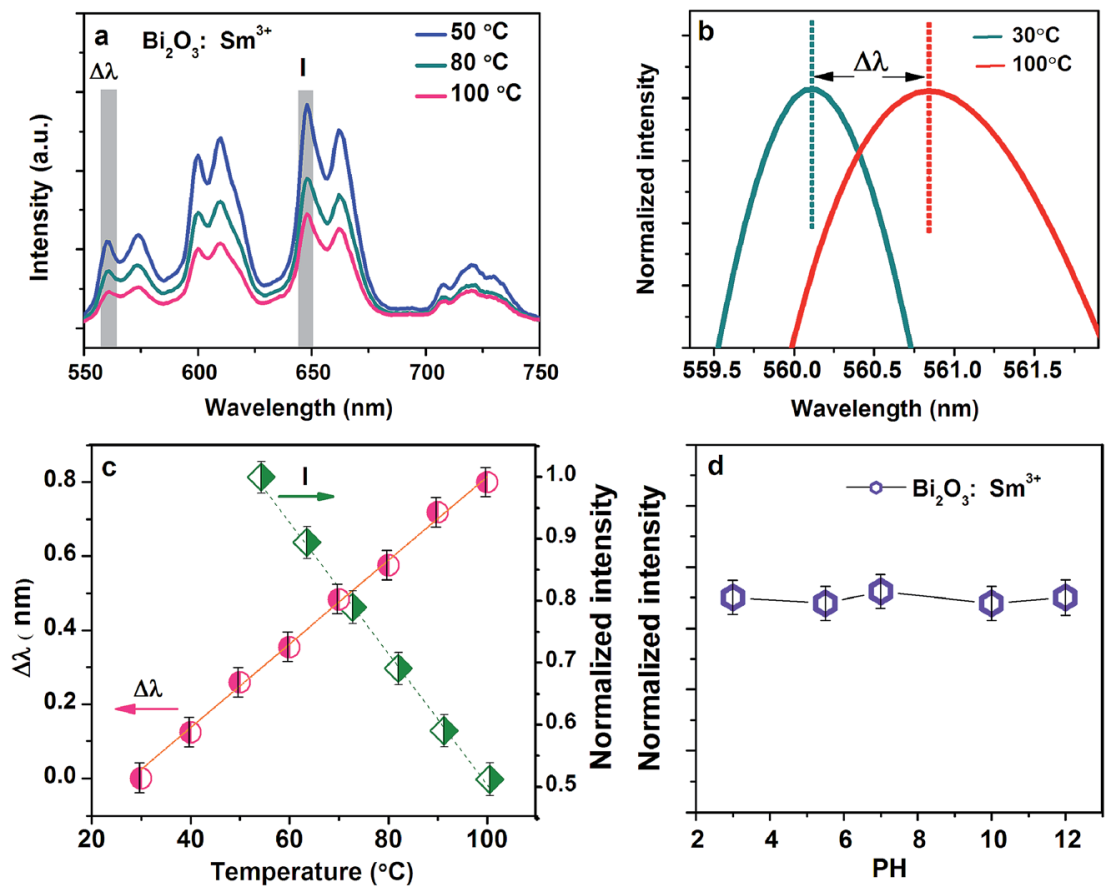

Fig. 6 The optothermal performance of $\mathrm{Bi}_{2} \mathrm{O}_{3}: \mathrm{Sm}^{3+}$ phosphor. (a) The $\mathrm{PL}$ spectra of the $\mathrm{Bi}_{2} \mathrm{O}_{3}: \mathrm{Sm}^{3+}$ phosphor obtained at 50,80 , and $100{ }^{\circ} \mathrm{C}$ as a representative example. (b) Temperature-induced spectral shift of $\mathrm{Bi}_{2} \mathrm{O}_{3}: \mathrm{Sm}^{3+}$ phosphor between 559 and $562 \mathrm{~nm}$. (c) The normalized intensity of the emission peak (I) at $563 \mathrm{~nm}$ and spectral shift $(\Delta \lambda)$ as a function of temperature. (d) Intensity variation of the emission peak at $653 \mathrm{~nm}$ as a function of $\mathrm{PH}$ value.

environment (Fig. 6d). Obviously, the emission intensity is constant and independent of the $\mathrm{pH}$ value. It is inferred that $\mathrm{Bi}_{2} \mathrm{O}_{3}: \mathrm{Sm}^{3+}$ phosphor is stable under the condition of an acid or alkaline system.

\section{Conclusion}

In conclusion, we synthesized a $\mathrm{Sm}^{3+}$-doped $\mathrm{Bi}_{2} \mathrm{O}_{3}$ phosphor. The result of theoretical calculation showed that $\mathrm{Bi}_{2} \mathrm{O}_{3}$ had a middle, direct band gap of $2.13 \mathrm{eV}$. We conducted the selfconsistent spectroscopic, photoelectric, and optothermal measurements of the representative $\mathrm{Bi}_{2} \mathrm{O}_{3}: \mathrm{Sm}^{3+}$ phosphor. The excitation spectrum was tailored via the tuning of the band gap. No emission behavior under the excitation of UV light (wavelength $<450 \mathrm{~nm}$ ) could be observed although distinct emission peak still existed. We also demonstrated the phenomena of temperature-induced population redistribution and temperature-induced spectral shift in the $\mathrm{Bi}_{2} \mathrm{O}_{3}: \mathrm{Sm}^{3+}$ phosphor. The emission intensity decreased with the increasing temperature, and the red-shift of emission peak at higher temperatures was considered. Maximum thermal sensitivity was attached as well $\left(1.13 \%{ }^{\circ} \mathrm{C}^{-1}\right)$. Moreover, the $\mathrm{Bi}_{2} \mathrm{O}_{3}: \mathrm{Sm}^{3+}$ sample showed an excellent current response under the excitation of $460 \mathrm{~nm}$ and had a linear temperature sensing range with the increasing intensity of the excitation source. Further research on nanocrystallization, which is expected to open up an actual utilization of the as-synthesized phosphor in the visualization of the structural and functional processes in biological living tissue and optical and optoelectronic device, is still in progress.

\section{Conflicts of interest}

There are no conflicts to declare.

\section{Acknowledgements}

This work was financially supported by the National Natural Science Foundation of China (Grant No. 51602063, 21671045) and Guangdong Natural Science Foundation (Grant No. 2014A030310444). This work was also supported by the Guangdong High-level personnel of special support program and Open Fund of the State Key Laboratory of Luminescent Materials and Devices (South China University of Technology).

\section{References}

1 L. Sun, Y. Qiu, T. Liu, J. Z. Zhang, S. Dang, J. Feng, Z. Wang, H. Zhang and L. Shi, ACS Appl. Mater. Interfaces, 2013, 5, 9585-9593.

2 W. Shao, G. Chen, A. Kuzmin, H. L. Kutscher, A. Pliss, T. Y. Ohulchanskyy and P. N. Prasad, J. Am. Chem. Soc., 2016, 138, 16192-16195.

3 P. Pust, V. Weiler, C. Hecht, A. Tucks, A. S. Wochnik, A. K. Henss, D. Wiechert, C. Scheu, P. J. Schmidt and W. Schnick, Nat. Mater., 2014, 13, 891-896.

4 Y. Zhuang, J. Ueda, S. Tanabe and P. Dorenbos, J. Mater. Chem. C, 2014, 2, 5502.

5 M. Peng and L. Wondraczek, J. Mater. Chem., 2009, 19, 627630. 
6 L. Lin, G.-Q. Gao, Q. Zhu and A.-W. Xu, J. Mater. Chem. A, 2015, 3, 12845-12851.

7 X. D. Wang, O. S. Wolfbeis and R. J. Meier, Chem. Soc. Rev., 2013, 42, 7834-7869.

8 S. Gu, K. Ding, J. Pan, Z. Shao, J. Mao, X. Zhang and J. Jie, J. Mater. Chem. A, 2017, 5, 11171-11178.

9 M. E. Lee and A. M. Armani, ACS Sensors, 2016, 1, 1251-1255.

10 D. Gedamu, I. Paulowicz, S. Kaps, O. Lupan, S. Wille, G. Haidarschin, Y. K. Mishra and R. Adelung, Adv. Mater., 2014, 26, 1541-1550.

11 D. Ruiz, B. Rosal, M. Acebrón, C. Palencia, C. Sun, J. Cabanillas-González, M. López-Haro, A. B. Hungría, D. Jaque and B. H. Juarez, Adv. Funct. Mater., 2017, 27, 1604629.

12 D. Jaque and F. Vetrone, Nanoscale, 2012, 4, 4301-4326.

13 H. D. A. Santos, D. Ruiz, G. Lifante, C. Jacinto, B. H. Juarez and D. Jaque, Nanoscale, 2017, 9, 2505-2513.

14 Y. Guo, S. Gu, X. Feng, J. Wang, H. Li, T. Han, Y. Dong, X. Jiang, T. D. James and B. Wang, Chem. Sci., 2014, 5, 4388-4393.

15 E. Hemmer, P. Acosta-Mora, J. Méndez-Ramosb and S. Fischer, J. Mater. Chem. B, 2017, 5, 4365-4392.

16 Q. H. Cui, Y. S. Zhao and J. Yao, Chem. Sci., 2014, 5, 52-57. 17 M. Peng, N. Zhang, L. Wondraczek, J. Qiu, Z. Yang and Q. Zhang, Opt. Express, 2011, 19(21), 20799-20807.

18 M. Peng, J. Qiu, D. Chen, X. Meng and C. Zhu, Opt. Express, 2005, 13(18), 6892-6898.

19 X. Wang, S. Zhou and L. Wu, J. Mater. Chem. C, 2014, 2, 57525758.

20 Q. Yu, F. Chen, T. Xu, S. Dai and Q. Zhang, J. Non-Cryst. Solids, 2013, 378, 254-257.

21 A. L. J. Pereira, D. Errandonea, A. Beltrán, L. Gracia, O. Gomis, J. A. Sans, B. García-Domene, A. Miquel-Veyrat, F. J. Manjón, A. Muñoz and C. Popescu, J. Phys.: Condens. Matter, 2013, 25, 475402.

22 H. A. Harw, Z. Anorg. Allg. Chem., 1978, 444, 151-166.
23 R. D. Shannon, Acta Crystallogr., Sect. A: Cryst. Phys., Diffr., Theor. Gen. Crystallogr., 1976, 32, 751.

24 F. Chen, J. Cheng, S. Dai and Q. Nie, J. Non-Cryst. Solids, 2013, 377, 151-154.

25 D. Wood and J. Tauc, Phys. Rev. B: Solid State, 1972, 5, 31443151.

26 A. E. Morales, E. S. Mora and U. Pal, Rev. Mex. Fis., 2007, 53, 18-22.

27 M. Maheshwary, B. P. Singh and R. A. Singh, New J. Chem., 2015, 39, 4494-4507.

28 M. Peng, C. Zollfrank and L. Wondraczek, J. Phys.: Condens. Matter, 2009, 21, 285106-285112.

29 M. Xin, D. Tu, H. Zhu, W. Luo, Z. Liu, P. Huang, R. Li, Y. Cao and X. Chen, J. Mater. Chem. C, 2015, 3, 7286-7293.

30 H. Guan, G. Liu, J. Wang, X. Dong and W. Yu, Dalton Trans., 2014, 43, 10801.

31 Y. Liu, G. Liu, J. Wang, X. Dong and W. Yu, New J. Chem., 2015, 39, 8282-8290.

32 B. Dong, B. Cao, Y. He, Z. Liu, Z. Li and Z. Feng, Adv. Mater., 2012, 24, 1987-1993.

33 J. Feng, K. Tian, D. Hu, S. Wang, S. Li, Y. Zeng, Y. Li and G. Yang, Angew. Chem., Int. Ed., 2011, 50, 8072-8076.

34 H. D. Santos, D. Ruiz, G. Lifante, C. Jacinto, B. H. Juarez and D. Jaque, Nanoscale, 2017, 9, 2505-2513.

35 F. Ye, C. Wu, Y. Jin, Y. H. Chan, X. Zhang and D. T. Chiu, J. Am. Chem. Soc., 2011, 133, 8146-8149.

36 B. del Rosal, E. Ximendes, U. Rocha and D. Jaque, Adv. Opt. Mater., 2017, 5, 1600508.

37 Y. Li, M. Gecevicius and J. Qiu, Chem. Soc. Rev., 2016, 45, 2090-2136.

38 F. Menges, P. Mensch, H. Schmid, H. Riel, A. Stemmer and B. Gotsmann, Nat. Commun., 2016, 7, 10874.

39 Y. Li, Y. Li, R. Chen, K. Sharafudeen, S. Zhou, M. Gecevicius, H. Wang, G. Dong, Y. Wu, X. Qin and J. Qiu, NPG Asia Mater., 2015, 7, e180.

40 Y. Li, S. Zhou, Y. Li, K. Sharafudeen, Z. Ma, G. Dong, M. Peng and J. Qiu, J. Mater. Chem. C, 2014, 2, 2657-2663. 